\title{
Do seasonal microbiome changes affect infection susceptibility, contributing to seasonal disease outbreaks?
}

\author{
Adrian Stencel $₫$
}

Institute of Philosophy, Jagiellonian University, Kraków, Poland

Correspondence

Adrian Stencel, Institute of Philosophy, JagielIonian University, Kraków, Poland.

Email:adstencel@gmail.com

Funding information

Narodowe Centrum Nauki, Grant/Award

Number: 2017/27/B/HS1/00290

\begin{abstract}
The aim of the present paper is to explore whether seasonal outbreaks of infectious diseases may be linked to changes in host microbiomes. This is a very important issue, because one way to have more control over seasonal outbreaks is to understand the factors that underlie them. In this paper, I will evaluate the relevance of the microbiome as one of such factors. The paper is based on two pillars of reasoning. Firstly, on the idea that microbiomes play an important role in their hosts' defence against infectious diseases. Secondly, on the idea that microbiomes are not stable, but change seasonally. These two ideas are combined in order to argue that seasonal changes in a given microbiome may influence the functionality of the host's immune system and consequently make it easier for infectious agents to infect the host at certain times of year. I will argue that, while this is only a theoretical possibility, certain studies may back up such claims. Furthermore, I will show that this does not necessarily contradict other hypotheses aimed at explaining seasonal outbreaks; in fact, it may even enhance them.

KEYWORDS

infectious diseases, microbiome, seasonality, viruses
\end{abstract}

\section{INTRODUCTION}

The widespread belief that some diseases have a seasonal character has been with us at least since antiquity, as Hippocrates himself noted this tendency. ${ }^{[1]}$ Currently, we know that seasonal illnesses may be caused by agents, such as influenza viruses, which infect a much greater number of people during winter, ${ }^{[2-4]}$ corresponding to the popular expression "flu season." However, these seasonal diseases can also be caused by non-infectious factors. For example, Oberg et al. found a seasonal association with ischaemic stroke, for which the peak of occurrence was reached in mid-May. ${ }^{[5]}$ Even though both tendencies are interestingthe present paper focuses on infectious diseases only.

What do we really mean when we say that infectious diseases are characterised by seasonality? Not that all infectious diseases peak in a host population at the same time, but rather that the infectious agents that cause diseases in a host population are characterised by their own seasonal windows of intensified occurrence in a host population. These windows are usually contained within a single year, but some diseases, e.g., pertussis, caused in human populations by the bacteria Bordetella pertussis, may involve multi-annual outbreaks. ${ }^{[4]}$ Importantly, infectious diseases may vary between geographic locations and differ from other diseases within the same location. In the case of the human population in the Northern Hemisphere, outbreaks of infection with influenza viruses occur each winter, ${ }^{[2-4]}$ whereas infection with the chicken pox virus peaks each spring, ${ }^{[4,6]}$ and transmission of the polio virus has historically occurred in summer. ${ }^{[7]}$ Seasonal outbreaks in humans, marked by winter peaks, are also a feature of bacterial infections caused by pneumococcus. ${ }^{[8,9]}$ Seasonal outbreaks in human populations are not limited to temperate zones; for example, Levy and colleagues showed that rotaviruses in tropical regions infect the greatest number of individuals in cold and dry months. ${ }^{[10]}$ Furthermore, outbreaks are also different in different host species and are sometimes caused by agents other than the viruses to which we intuitively ascribe such events (see Table 1 for examples). However, not all diseases caused by infectious agents have a seasonal character. For instance, Skajja and colleagues showed that even though the 
TAB LE 1 We are familiar with the seasonality of infectious diseases in humans (some examples in the text); we even have popular phrases to refer to this, such as "flu season," and commonly associate them with viruses. However, seasonal outbreaks outside human populations are also widespread and may be caused by both viral and non-viral agents. This table presents some examples

\begin{tabular}{l} 
Examples of seasonal outbreaks of infectious \\
diseases in non-human populations \\
Sweden: seasonal outbreaks of the bacteria \\
Salmonella enterica, peaking in March, in humans, \\
domestic cats, and passerines. \\
Denmark: seasonal outbreaks of cowpox virus, \\
peaking between August and October, in captive \\
cheetahs in a safari park. \\
Etosha National Park, Namibia: seasonal outbreaks \\
of the bacterium Bacillus anthracis, peaking at the \\
end of the rainfall season, in plains zebras and \\
springboks. \\
United States: seasonal outbreaks of many \\
pathogens of honey bees. The peak of infection \\
with common honey bee viruses - black queen \\
cell virus (BQCV), bee paralysis virus (ABPV), and \\
sacbrood virus (SBV) - and with the \\
microsporidian Nosema occurred in the summer, \\
whereas levels of the trypanosomatid Crithidia \\
mellificae and Lake Sinai virus 2, a novel virus, \\
peaked in January. \\
Central Oklahoma, United States: seasonal \\
outbreaks of the fungus Batrachochytrium \\
dendrobatidis in amphibian populations of \\
different species increased during cooler months \\
(March, May, October) and decreased during \\
warmer months (June, August). \\
\hline
\end{tabular}

aetiology of inflammations of the heart (broadly classified as pericarditis, myocarditis, and endocarditis) is predominantly infectious, these diseases are not characterised by seasonal outbreaks. ${ }^{[11]}$ Furthermore, the seasonality of certain pathogens may be "context-dependent." For example, the seasonality of the hepatitis $C$ virus has been observed only in some countries. ${ }^{[12]}$ In other cases, more research is needed. For instance, Sajadi et al. have pointed out that COVID-19 may be marked by seasonal differences in activity, ${ }^{[13]}$ similarly to other common human coronaviruses, ${ }^{[14]}$ which usually cause symptoms of the common cold, have been shown to display marked winter seasonality between December and April, and are undetectable in summer months in temperate regions. However, certain other coronaviruses, such as MERS and SARS, do not appear to follow a seasonal pattern. ${ }^{[13]}$ Thus, it is too soon to reach any decisions regarding the seasonality of COVID-19. Nevertheless, it seems that the seasonality of infections is a widespread phenomenon.

All of the above shows that there is a recurrent theme that needs to be explored. Mainly, what are the factors that contribute to intensified occurrences of infectious diseases in certain seasons? In other words, what causes the seasonality of infectious diseases? Table 2 presents some popular ideas currently in scientific circulation that have been put forward to explain this phenomenon. Interestingly,
TAB LE 2 Classic ideas aimed at explaining the factors causing seasonal outbreaks of infectious diseases

\begin{tabular}{l}
$\begin{array}{l}\text { Factors linked to the seasonality of infectious } \\
\text { diseases }\end{array}$ \\
$\begin{array}{l}\text { The low level of absolute humidity that comes with } \\
\text { winter is linked to influenza outbreaks. }\end{array}$ \\
$\begin{array}{l}\text { A factor seemingly connected with seasonal } \\
\text { outbreaks of influenza is the drop in the } \\
\text { production of vitamin D in winter. }\end{array}$ \\
$\begin{array}{l}\text { Low temperatures enhance the survival of } \\
\text { rotaviruses and noroviruses and thus may be } \\
\text { linked to their winter peaks. }\end{array}$ \\
$\begin{array}{l}\text { Behavior of hosts: for example, children } \\
\text { congregating during school terms are linked to } \\
\text { seasonal outbreaks of measles. }\end{array}$ \\
\hline
\end{tabular}

they are mostly based on information from the Northern hemisphere, which shows that more work is needed to uncover the factors that cause outbreaks in other latitudes, such as in tropic regions. This is a very important issue, because one way to assume more control over seasonal outbreaks is to understand the factors that cause them and to take proper precautions every season. However, if we look at all of the examples from Table 1 and from the preceding paragraph, we soon realise that we are dealing with a hugely diverse phenomenon, involving factors including the various locations of seasonal outbreaks, the different pathogens that cause them (bacteria, viruses, etc.), and the various victims of these outbreaks. Therefore, it is very unlikely that a single factor could explain why a great many infectious agents are characterised by seasonal patterns of higher incidence. This was shown clearly by Martinez, ${ }^{[4]}$ who, in her review of the seasonality of infectious diseases in humans, pointed out that the seasonality of many infectious diseases is often caused by a combination of different factors.

The aim of this paper is to show that another factor has to be taken into account if we wish to solve the puzzle of seasonality: microbiomes. Mainly, I will try to show that part of the mystery surrounding the seasonality of infectious diseases can be explained via reference to internal changes in host microbiomes This idea, although it has attracted insufficient attention in the study of seasonality, for example, it has not been mentioned as one of the potential factors in review papers, ${ }^{[4,22,24-26]}$ sometimes appears in research papers as a possible explanation for the results. ${ }^{[27-29]}$ However, it has never been put forward as a general explanation of the seasonality of infectious diseases. The aim of the present paper is to show the theoretical plausibility indeed, to flesh out the conceptual basis - of this idea.

For a microbiome to be a contributing factor to an explanation of the seasonal character of infectious diseases, it must be characterised by three things. It must (i) make an organism more or less susceptible to infectious diseases and (ii) undergo seasonal changes in composition and/or diversity, in parallel to outbreaks of these diseases. In the next two sections I will show that microbiomes may indeed be characterised by these properties. However, this is still insufficient, because there must also be a proper relationship between (i) and (ii). Specifically, (iii) 
TAB LE 3 Selected examples of the role the microbiome may play in the physiology of a host

Role of the microbiome in the physiology of a host
Involvement in the process of digestion. For
example, it has been revealed that the intestinal
microbiome in humans is involved in the digestion
of certain foods that cannot be digested by the
stomach or intestines.
Involvement in protection against pathogens. For
example, in frogs, the skin microbiome protects
against a pathogenic fungus.
Involvement in the proper development of the
immune system. For example, members of the gut
microbiome may promote the differentiation of
anti-inflammatory regulatory T cells (Treg).
Influence on the behavior of the host. For example,
the gut microbiome may be linked to mental
health and contribute to the development of
depression.

seasonal changes in microbiomes must influence their immunological role, making organisms more or less susceptible to infectious diseases. This is more difficult to demonstrate; however, in the third section I will show that some evidence exists giving us reason to "re-think" this explanation for the seasonality of infectious diseases and, thus, to take microbiomes into account.

\section{MICROBIOME PLAYS AN IMPORTANT ROLE IN HOST DEFENCE AGAINST INFECTIOUS DISEASES}

The term microbiome, referring to a community of symbiotic microorganisms, can be used in various research contexts. For example, Gohli and colleagues studied the microbiomes of subway stations and their seasonal variation in Oslo by performing high-throughput 16S rRNA gene sequencing of air and surface samples from 16 stations across all four seasons. ${ }^{\left[{ }^{[30]}\right.}$ Here, in using the term microbiome, I refer to the community of all symbiotic microorganisms living in and on the body of a multicellular organism, such as a plant or animal. The number of these symbiotes is enormous, very likely equal to the number of host cells. ${ }^{[31]}$ The number of unique genes that the microbiome provides for the host is even greater. For example, microbes in the human gastrointestinal tract alone may contain from 150 to 500 times more genes than human DNA. ${ }^{[32,33]}$ Thus, the microbiome appears to be an outstanding source of genetic variation for multicellular organisms, as has been observed recently in many dimensions. On one hand, some scientists have argued that this finding completely changes our understanding of the process and history of evolution. ${ }^{[34-36]}$ On the other hand, many have emphasised its importance to the physiology of the host. ${ }^{[32,33,37-40]}$ Table 3 provides some concrete examples.

Among the many roles microbiome might play in the physiology of the host, an especially important one is influencing the functionality of the immune system. ${ }^{[32,33,37,44,47]}$ The immunological system, a complex and important part of the organism, may be engaged in many vital functions, such as defence against pathogens or establishment and maintenance of boundaries between the organism and its environment. ${ }^{[33,48]}$ It appears that microbiome is involved in many of these activities, for example, in the maturation of the immune system, ${ }^{[33,45]}$ and defence against infectious agents. ${ }^{[47,49,50]}$ It may also be linked to certain disorders, such as allergies. ${ }^{[33,51]}$ These activities are extremely interesting and important; however, as the role of the microbiome in infectious diseases is the primary subject of the present paper, I will briefly say more about this by citing some examples.

The first example comes from the study of rotaviruses, which are problematic because they cause severe diarrhoea in children and lead to approximately 600,000 deaths every year. [52] Thus, finding a way to deal with these viruses is an urgent task. In recent years it has been observed that one way to overcome these problems is to focus on microbiomes that may work quite well as a shield against rotaviruses. ${ }^{[33,49,50]}$ In one study, Zhang and colleagues investigated this potential role of microbiome in mice through studying their infection and protection mechanisms against highly contagious pathogenic rotaviruses. ${ }^{[49]}$ This team's hypothesis was based on the fact that flagellin, an element of bacterial flagella, activates host genes engaged in defence in intestinal epithelial cells (IECs), ${ }^{[53]}$ where the rotaviruses predominantly penetrates and replicates. ${ }^{[54]}$ The study showed that treating germ-free mice with bacterial flagellin not only prevented mice from being infected with rotaviruses but also cured previously-infected mice. The molecular mechanism behind this process requires the flagellin receptors Toll-like receptor 5 (TLR5) and NOD-like receptor C4 (NLRC4) and involves production of interleukin22 and interleukin-18.

The second example shows that microbiomes can also protect their hosts from infectious diseases by directly inhibiting their colonisation. Many bacteria found in the intestines of hosts are capable of providing this protection, ${ }^{[47,49,55]}$ through either competing for nutrients with pathogens or producing certain inhibiting substances. The former mechanism is exemplified by Bacteroides thetaiotaomicron, ${ }^{[56]}$ which live in the intestines of their hosts (mice) and feed on carbohydrates. The same resources are used by the pathogenic bacteria Citrobacter rodentium. Thus, when a mouse with $B$. thetaiotaomicron in its intestines is infected by $C$. rodentium, the latter cannot grow rapidly, because the necessary resources are being used by the former. Indeed, $B$. thetaiotaomicron is much better at acquiring these resources and thus outcompetes $C$. rodentium. Basically, it can be said that the presence of $B$. thetaiotaomicron leads to the starvation of pathogenic bacteria. Another way of protecting a host from colonization by pathogenic bacteria, as previously mentioned, is through the production of inhibiting substances. This happens when intestinal microbiome produce certain substances that modify the intestinal environment and consequently influence the growth and/or virulence of the relevant pathogen, as exemplified by the production of small bioactive molecules that can act on different parts of the intestine. These substances include bacteriocins - small antimicrobial peptides that can selectively (depending on the bacteriocin in question) kill competing bacteria. ${ }^{[57]}$ For example, Bacillus thuringiensis produces a bacteriocin (thuricin $\mathrm{CD}$ ) that 
directly targets spore-forming members of the classes Bacilli and Clostridia. ${ }^{[58]}$

\section{THE MICROBIOME IS CAPABLE OF UNDERGOING SEASONAL CHANGES}

\section{Multiple factors influence on the structure of microbiome}

Recent research has shown that a microbiome may undergo changes in community structure due to the influence of a multitude of factors. ${ }^{[37,59,60]}$ These changes do not always make a great deal of difference, as various taxa are capable of playing the same role in the physiology of the host, ${ }^{[36,61]}$ but in some cases they may modify the microbiome's proper functionality. ${ }^{[51,62]}$ Among the factors influencing the structure of a microbiome are antibiotics, ${ }^{[60,63]}$ diet, ${ }^{[27,32,59,64,65]}$ temperature, ${ }^{[28,66,67,68]}$ humidity, ${ }^{[69,70]}$ and even the host's production of vitamin $D^{[71,72]}$ In humans, for example, treatment with vancomycin causes depletion of most components of a gut microbiome, such as Bacteroidetes, and is associated with increases in species of Proteobacteria linked with infectious processes. ${ }^{[63]}$ Another factor one of the most important - is diet. For example, a vegetarian diet is linked with the dominance of genera capable of metabolising insoluble carbohydrates, such as Ruminococcus, Roseburia, and Eubacterium, ${ }^{64]}$ and has been associated with a decline in Firmicutes and an increase in Bacteroides. ${ }^{[59]}$

These examples represent the tip of the iceberg, as there are many other factors that shape the structure of a microbiome. Of greater interest from the perspective of this section, however, is the fact that microbiomes can also change temporarily at certain times of the year. Indeed, they may undergo seasonal changes in structure. This should not be surprising, as all of the factors that influence microbiomes are also subject to change during the year. We know that temperature and humidity change, but diet, ${ }^{[73,74]}$ and even prescriptions of antibiotics can also undergo seasonal changes to some extent. ${ }^{[75,76]}$ All of this shows that microbiomes have the potential to undergo recurrent seasonal changes along with the factors that modulate their structures. Although this subject has not received much attention, some researchers suggest that this occurs in both humans and other species. Studies on this question are becoming ever more important, since, as Koliada and colleagues noted ${ }^{[73]}$, the focus on microbiomes at just one point in the year may obfuscate their dynamic nature. Let me present some examples to provide evidence for such claims, beginning with some research carried out on humans.

\section{Microbiome undergoes seasonal changes}

Let's start by presenting support for the idea that the seasonality of microbiomes is observable in our species. The most detailed data comes from a study of isolated groups. For example, Davenport and colleagues studied a population of Hutterites, ${ }^{[74]}$ a group of ethno- religious Anabaptists living in North America. Hutterites live and eat together, and thus constitute a communal group; as a result, dietary patterns are almost identical throughout the group as well as throughout the year, one exception being access to fresh fruits and vegetables in the summer and autumn months. In their study, they reported that the Hutterites' gut microbiome is generally stable within individuals at a given time, but there are wide differences in its composition over the seasons. Mainly, these researchers observed significant increases in Bacteroidetes and decreases in Actinobacteria and Firmicutes in summer compared to winter faecal samples. The main factor explaining this change in the gut microbiome, according to the researchers, is a shift in diet; however, other factors related to seasonality very likely play a role as well. Similar results were obtained in the study of the Hadza huntergatherers of Tanzania. Mainly, the gut microbiomes from dry seasons in sequential years were indistinguishable from one another, yet were clearly different from the gut microbiomes from the intervening wet season. ${ }^{[77]}$

Although the most reliable research is based on studies of isolated groups, more and more research is focusing on wider approaches. For example, in their study of middle-aged Japanese people, Hisada and colleagues found seasonal changes in the gut microbiome. ${ }^{[78]}$ Mainly, they showed that changes in the composition of Bifidobacterium are of a seasonal character, very likely driven by changes in consumption of fermented milk. In another study on a human Mongolian population, ${ }^{\text {[9] }}$ seasonal changes in the composition of the gut microbiome appeared more often in the Khentii pasturing area, where the dietary pattern is simple and varied throughout the year, than in Tuw Prefecture and Ulan Bator, where dietary structure is diverse and stable. Another study indicating the seasonal character of the gut microbiome composition was conducted in Ukraine. ${ }^{[73]}$ Among many discoveries, the authors found that Actinobacteria abundance was much higher in summer in comparison to other seasons, whereas the abundance of Bacteroides was significantly reduced in summer compared to other seasons. Furthermore, there is also indirect evidence for the seasonality of microbiomes. For example, in a US population, Korownyk and colleagues demonstrated seasonal modulation in odours known to be associated with the structure of the microbiome. ${ }^{[80]}$

The seasonal variation in microbiomes concerns not only humans but also other species that harbour symbiotic microorganisms. One study revealed seasonality in the gut microbiome of Tibetan macaques (Macaca thibetana). Sun and colleagues showed that, ${ }^{[62]}$ in winter, numbers of the genus Succinivibrio, which promotes the digestion of cellulose and hemicellulose, significantly increase, whereas in spring, abundance of the genus Prevotella, associated with the digestion of carbohydrates and simple sugars, rises markedly. Seasonal variation in microbiomes was noted as well in cases of amphibians. For example, Longo and colleagues discovered that skin microbiomes undergo seasonal changes in Lithobates yavapaiensis and Eleutherodactylus coqui. ${ }^{[29]}$ Mainly, during winter these microbiomes are characterised by greater bacterial diversity.

Seasonal variation in microbiomes is linked not only to animals, but occurs as well in plants. For instance, Ou and colleagues showed that, ${ }^{[81]}$ in mulberry trees, a seasonal shift takes place in the 
composition of endophytes, i.e. microbes living in plant tissue. In spring, the majority of endophytes comprised Proteobacteria and Actinobacteria; in autumn, Proteobacteria only. In another study, Copeland and colleagues investigated seasonal changes in the leaf microbiomes of three agricultural crop species commonly farmed in Ontario, ${ }^{[82]}$ Canada: Glycine max (soybean), Brassica napus (canola), and Phaseolus vulgaris (common bean). These researchers discovered that, at the beginning of the summer, the microbiomes were very diverse and more similar to the soil microbiome. As the summer continued, they became differentiated and significantly less diverse, incorporating a greater proportion of leaf-specific taxa.

\section{CAN CHANGES IN THE MICROBIOME HELP TO EXPLAIN OUTBREAKS OF INFECTIOUS DISEASES?}

\section{The Causal role of microbiome in the outbreaks of infectious diseases}

In the previous parts of this paper I presented three premises present in the literature. To review them: (I) infectious diseases have a seasonal character; (II) microbiomes can help hosts to defend against infectious agents; (III) to some extent, the structures of microbiomes undergo seasonal changes. Combining these three premises, we arrive at a very interesting idea, namely, that seasonal changes in the microbiome may render its host more susceptible to infectious agents and thus contribute to seasonal outbreaks of infectious diseases.

I believe the research I presented in the last section provides a strong basis for putting forward this idea, which I will try to elaborate in this section. Firstly, I will show that we should exercise caution in this regard, because the vector of causation may be different. Then I will show that seasonal changes in the structure of the microbiome may, at least sometimes, be responsible for the seasonal outbreaks of infectious diseases. Finally, I will try to show that this idea is consistent with others aiming to explain seasonal outbreaks and makes it possible to re-interpret them in the light of microbiomics.

We should start with the simple statement that in microbiome studies experimental evidence suggests correlation, but it is disputed whether causation can be inferred from it. ${ }^{[83-85]}$ The fact that an outbreak of infectious disease accompanies seasonal changes in the microbiome does not mean per se that the latter causes the former. The converse (i.e. infectious outbreaks may cause changes in microbiomes) is also a justified conclusion. One obvious reason for this is that, following infection, people might change their diets, which are among the main modulators of, for example, the gut microbiome. $[27,32,59,64,65]$ For example, Groves and colleagues showed that changes in the gut microbiome occurred following viral lung infection in mice. ${ }^{[86]}$ This was very likely caused by immune-mediated inappetence that influenced the diet of the mice and, as a result, the structure of the microbiome. Another reason may be that, in the course of infections, people take medications that potentially influence the microbiome. In a recent meta-analysis, Vila and colleagues showed that many com- mon medications alter the gut microbiome. ${ }^{[87]}$ Alternatively, changes in microbiome composition and outbreaks of infectious diseases may be correlated because they may be the results of what philosophers call a common cause. ${ }^{[85,88,89]}$ This was pointed out by Lynch and colleagues as a better explanation for some studies that see a correlation between changes in phenotype and changes in the composition of the microbiome. ${ }^{[85]}$

The above arguments show that the ability to see a relationship between changes in microbiomes and some aspect of the host's phenotype does not imply that causality is easy to establish. This raises a question connected with the relationship between the seasonality of microbiomes and that of infectious diseases. Might the former be the cause of the latter, at least in some instances? Sadly, no studies are likely to demonstrate unequivocally that seasonal changes in microbiomes play a causal role in seasonal outbreaks. However, I will argue that this is a valid hypothesis that should be given more attention in the study of seasonality of outbreaks by indirect way. Mainly, I will attempt to show that factors that undergo seasonal changes may influence the immunological properties of microbiomes. This suggests that it is justified to take microbiomes into account when attempting to explain seasonal outbreaks. Furthermore, where possible, I will mention studies that are on the right track towards discovering the causal role of microbiomes in seasonal outbreaks of infectious diseases. I will show this first by demonstrating the influence of diet. Then I will analyse the influence of temperature and production of vitamin $D$, factors that have been put forward in hypotheses attempting to explain the seasonal outbreaks of infectious diseases. I have chosen these factors because it is uncertain whether the introduction of microbiomes into the discussion call these ideas into question or potentially enrich them. I favour the latter possibility, as it provides an alternative explanation for the process whereby these factors lead to seasonal outbreaks (Figure 1). I will now show this by linking microbiomes to factors aimed at explaining the seasonality of infectious diseases.

Let us start with the most important modulator of the structure of microbiomes, i.e., diet, which is known to impact microbiomes, especially in the gut, ${ }^{[27,32,59,64,65,90]}$ and, as noted earlier, is subject to seasonal changes that influence their structures. ${ }^{[62,74,75,78]}$ Knowing this, we can ask whether changes in diet have an impact on the immunological properties of microbiomes. I believe there is some research showing the potential of diet in this respect. For instance, Trompette and colleagues, ${ }^{[91]}$ in a study on mice, found that dietary fermentable fibre content changed the composition of gut and lung microbiomes through altering the ratio of Firmicutes to Bacteroidetes, which influenced the microbiomes' immunological properties. Mice on a high-fibre diet were characterised by increased circulating levels of short-chain fatty acids (SCFAs) and were protected against allergic inflammation in the lungs, whereas a low-fibre diet decreased levels of SCFAs and exacerbated allergic airway disease. In the first case, the increased level of SCFAs was caused by the gut microbiome, which metabolised the fibre. In another study, Desai and colleagues discovered that feeding mice a fibre-free diet promoted the expansion and activity of mucousdegrading bacteria in the colon, ${ }^{[92]}$ leading to increased susceptibility to infections in comparison to fibre-fed controls, because the gut 


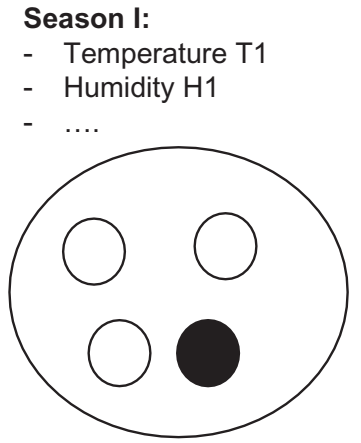

No infection

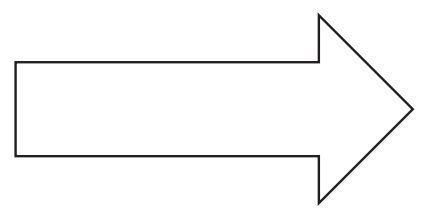

\section{Season 2}

- Temperature T2

- Humidity H2

- $\quad$....
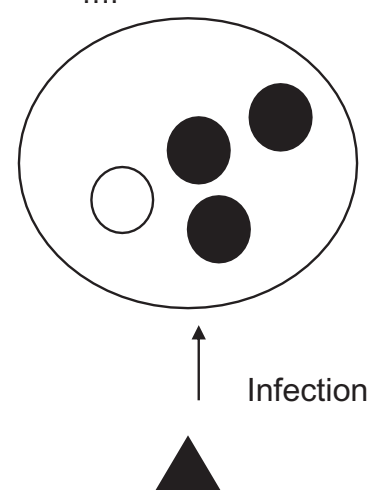

FIGURE 1 A reference to a microbiome can "re-interpret" the classic explanations of the seasonality of infectious diseases (like temperature, humidity, etc.). Microbiome is involved in the defence against infectious diseases and is very plastic, because external factors can change its composition. Thus, as during seasons external factors are being changed they might affect the microbiome and its potential in defence against infectious agents. As result, it contributes to outbreak of infectious disease in next season, as pictured above. Big circles refer to host, small to microbiome, triangles represent viruses. Colors refer to different members of the microbiome, whose abundance is changing during season making the host suceptible to infections.

microbiome used host-secreted mucous glycoproteins as a nutrient source, leading to erosion of the colonic mucous barrier. As a result, dietary fibre deprivation, along with a fibre-deprived, mucous-eroding microbiome, led to greater epithelial access for the mucosal pathogen, Citrobacter rodentium, resulting in lethal colitis.

This, of course, shows only that changes in the diet lead to changes in the immunological properties of microbiomes, as a result of changes in their structures. However, the question is whether such changes can cause seasonal outbreaks. As I noted previously, it is hard to point out paradigm examples, but I believe that some studies are on the right track in terms of unravelling the causality here. One such study was conducted by Maurice and colleagues, ${ }^{[27]}$ who suggested that seasonal changes in the structure of the gut microbiome of wood mice (Apodemus sylvaticus) in the United Kingdom over a two-year period was very likely due to a transition from a diet based on insects to one based on seeds. The most interesting discovery involved the observation that the abundance of Lactobacillus increased in spring and decreased in autumn. This was correlated with a reduction in the abundance of Helicobacter in spring and an increase in autumn. The authors suggested that this might indicate a connection - mainly, that Lactobacillus might be involved in protection against Helicobacter infection and that the autumnal decline in its abundance facilitated infection in mice by Helicobacter. Of course, empirically, only the correlation was proven; other explanations were possible at this point in the research. However, this is undoubtedly an interesting case to be explored in future in experimental settings, as laboratory studies have shown that Lactobacillus confers protection against infectious diseases. ${ }^{\text {[93,94] }}$ Thus, one possible explanation is that diet-induced seasonal changes in the abundance of Lactobacillus lead to seasonal outbreaks of Helicobacter.

\section{Re-interpreting other hypotheses in the light of microbiomics}

One factor that has been linked to seasonal outbreaks of influenza are seasonal declines in the production of vitamin $D,{ }^{[95,20]}$ which plays an important role in the functionality of the immune system. ${ }^{\text {[96,97] }}$ Production of this vitamin not only may help fight infectious diseases but also may be involved in defence against infection. However, because it relies on solar radiation, which varies over the seasons, as a trigger, its level of production is not consistent during the year. Therefore, according to this idea, during the colder months, production of vitamin D declines, influencing the immune system, and as a result individuals become more susceptible to infection. Then, during the warmer months, vitamin D production rises, boosting the immune system and preparing organisms to fight infectious agents.

However, this is not the only way vitamin D can influence the immune system. It may also influence the microbiome, and this in turn may weaken an organism's immune system. More and more research shows that vitamin D may alter gut microbiome composition. ${ }^{[71]}$ How? For example, binding of the active form of vitamin $D$, calcitriol (also known as $1,25(\mathrm{OH}) 2 \mathrm{D}$ ), induces the production of antimicrobial peptides by macrophages. ${ }^{[71,72]}$ The consequent selective killing of pathogenic bacteria leads to greater opportunity for colonisation by "healthy" bacteria, which, as a result, may help to fight infectious agents, as this (as I showed in the second section of this chapter) is one of the microbiome's roles. Therefore, seasonal declines in the production of vitamin D may influence gut composition, which in turn may make organisms more or less susceptible to infectious agents. This may help to explain why seasonal outbreaks are correlated with declines in the production of vitamin $D$. 
Another factor that has been frequently linked to seasonal outbreaks involves changes in temperature from one season to another. $[3,4,98]$ However, the issues of which temperatures cause seasonal outbreaks, by means of which mechanisms, are not yet totally clear. On one hand, there is reason to think that low temperatures influence seasonal outbreaks, which frequently emerge during the winter months, in some way. ${ }^{[3,4,20]}$ For example, low temperatures enhance the survival of rotaviruses and noroviruses, and thus may be linked to their winter peaks. ${ }^{[21,22]}$ This is because viruses tend to be more stable at low temperatures, for example, within nasal passages, as the epithelial surface is cooled by colder ambient air. ${ }^{[99]}$ Moreover, the envelopes of viruses undergo physical changes at higher temperatures. Host immunology is as well influenced by the temperature. For example, at lower temperatures, cellular metabolic functions slow down, which consequently may reduce the frequency of ciliary beats, curb the secretion of mucous, and restrict phagocytosis. ${ }^{[99]}$ On the other hand, it appears that high temperatures may not diminish seasonal outbreaks. For example, research on mice shows that high temperatures mimicking summer heat may actually make a host more susceptible to viral infections. ${ }^{[26,100]}$ Thus, the relationship between outbreaks and temperature is not likely to be linear; other factors may be involved and may differ for different pathogens, especially in view of the fact that some seasonal outbreaks, such as those of West Nile virus, ${ }^{[28]}$ chicken pox, ${ }^{[4,6]}$ and even all six recent influenza pandemics occurring in the Northern Hemisphere in the period 1957-2009, occurred between spring and summer. ${ }^{\text {[26,101] }}$

One potential alternative mechanism by means of which low/high temperatures can make a host more susceptible to infection operates through influencing the microbiome, which may play a role in the defence against infectious diseases. Currently, more and more emerging research shows that changes in temperature may constitute an important modulator of gut microbiome. ${ }^{[67]}$ For instance research shows that rearing mice in temperatures mimicking summer heat weakens virus-specific adaptive immunity, although this can be partially restored by glucose or short-chain fatty acid supplementation, suggesting a role for diet and the microbiome in heat-mediated immune impairment. ${ }^{[26,100]}$ Similarly, there is some evidence suggesting that low temperatures can influence the immunity of a host; this may be mediated by the microbiome. One such study was done by Ferguson and colleagues, ${ }^{[102]}$ who showed that the spring field cricket Gryllus veletis undergoes seasonal changes in microbiome gut composition that are associated with changes in the physiology of the host. For instance, in experimental settings mimicking winter conditions (such as low temperatures), these researchers observed changes in the crickets' gut microbiomes associated with certain changes in immunological activity. Most interestingly, in winter, crickets were less likely to survive fungal infections, suggesting that exposure to low temperatures, through influencing the microbiome, may make a host more susceptible to infectious agents.

This shows only that temperature is capable of influencing the immunological properties of microbiomes. The question, however, is whether such changes can trigger seasonal outbreaks. Are there any field studies that indicate as much? Of course, as in the case of diet, there are no paradigm cases that might constitute unequivocal demon- strations, but some studies are on the right track. One was conducted by Novakova and colleagues, ${ }^{[28]}$ who studied microbial communities in 11 adult mosquito host species from six regions in southern Ontario, Canada. These researchers observed seasonal shifts in microbiomes that recurred consistently over the 3-year period of their study. A striking case, from the perspective of this paper, involved Culex pipiens. In this species, seasonal changes observed in the relative abundance of the symbiotic bacteria Wolbachia were driven mainly by a change in mean temperature that correlated negatively with abundance. This finding is consistent with other studies. ${ }^{[103]}$ More interesting, though, is that this seasonal change in the abundance of Wolbachia, which peaked in August in each year, was followed by an increase in West Nile virus (WNV). For the mosquito, harbouring this virus entailed fitness costs. ${ }^{[104]}$ The authors concluded that, at higher temperatures, Wolbachia abundance was reduced, leading to greater susceptibility to WNV in the subsequent generation. Again, empirically speaking, only the correlation was proven; other explanations were possible at this point in the research. However, this is undoubtedly an interesting case, to be explored in future in experimental settings, as laboratory studies have shown that Wolbachia confer protection against infectious diseases. ${ }^{[105,106]}$ Thus, temperature-induced seasonal changes in the abundance of Wolbachia may lead to seasonal outbreaks of West Nile virus.

I think these examples clearly show that, at least in theory, microbiomes are likely contributors to seasonal outbreaks of infectious diseases. Of course, the word microbiome is a very broad term and encompasses a wide range of phenomena. For example, we might distinguish skin, lung, and vaginal microbiomes. All of these microbiomes may be involved in seasonal outbreaks, but not at the same time (for instance, some parts of a microbiome might contribute to outbreaks caused by infectious agent $A$, others to those caused by B). Very likely, different parts of microbiomes will also prove relevant to seasonal outbreaks in different species; for instance, skin microbiomes appear to play an important role in amphibian immunology, ${ }^{[43,44]}$ whereas in mammals gut microbiomes appear more relevant. ${ }^{[92,93]}$ Furthermore, even though diet seems to be the most important modulator of microbiome structure, ${ }^{[27,32,59,64,65]}$ microbiomes can also be shaped by other factors, such as antibiotics, ${ }^{[60,63]}$ temperature, ${ }^{[28,66,67,68]}$ humidity, ${ }^{[69,70]}$ and even the host's production of vitamin D. ${ }^{[71,72]}$ This suggests that seasonal outbreaks to which microbiomes may contribute may be triggered by seasonal changes in different external factors. In other words, the question of whether microbiomes contribute to outbreaks and, if so, which parts of microbiomes and which external factors producing changes in microbiomes are relevant are details that depend on the species in question and must be empirically investigated. The main message of this paper is that such an investigation will have to take into account the justified possibility that microorganisms may play a causal role in outbreaks of seasonal infectious diseases.

Overall, this section has shown that we should seriously consider microbiomes, as they may change from season to season, which may influence their ability to fight infectious diseases. Furthermore, factors capable of modifying microbiomes (vitamin $\mathrm{D}$, temperature, etc.) have been suggested as contributors to seasonal outbreaks, suggesting 
that these modifications constitute a potential alternative mechanism whereby these factors render hosts more susceptible to infectious agents. I have offered some evidence here in favour of this idea, which, of course, requires a more "holistic" and dynamic view of an organism. In this view, an organism comprises the combination of a host and microbes (i.e., a holobiont), as has been proposed by many researchers, ${ }^{[37-39,107,108]}$ and may undergo changes in its functionality over the seasons that affect the microbes involved in its basic properties (such as immunology).

\section{CONCLUSIONS AND OUTLOOK}

In this paper I argued that seasonal changes in microbiomes may contribute to seasonal outbreaks of infectious diseases. This idea should be investigated empirically. This would require a mix of field studies and experimental studies, supplemented by theoretical modelling. Firstly, a connection between outbreaks of seasonal infectious diseases and the structure of microbiomes needs to be sought. As noted previously, some studies have already indicated such a connection. [27-29,109] However, these studies report mainly correlations, whereas causality is open to dispute. Thus, there is a need for follow-up studies aimed at determining, in experimental settings, whether a given state of a microbiome observed in nature during a seasonal outbreak renders the host more susceptible to infectious agents or whether this state is merely a by-product of the outbreak. I am not aware of any follow-up studies of this kind; however, studies that investigate the manner in which a microbiome renders its host more/less susceptible to infectious agents are conducted quite often, as was noted in the second section. ${ }^{[55-58]}$ Therefore, in principle it should be possible to design and conduct such studies. Finally, if we accept the idea that microbiomes are capable of involvement in seasonal outbreaks of infectious diseases, then our models aimed at predicting the dynamics of epidemics should incorporate a more inclusive view of individuals: specifically, that each individual comprises a host and a microbiome, and that some parts of a microbiome can be obtained from the environment or horizontally from other members of a given population, similarly to current modelling in evolutionary biology. ${ }^{[110,111]}$ This may influence our predictions and, in turn, our policy. Overall, it appears that a focus on microbiomes in studies of seasonal outbreaks of infectious diseases may result in a productive research programme that will open new research avenues or perhaps even lead to solutions of some old mysteries in the study of outbreaks of infectious diseases, just as a focus of this kind helped to clarify certain old inconclusive experiments in the study of speciation. ${ }^{[112]}$

\section{ACKNOWLEDGEMENTS}

I would like to thank Gregor Greslehner, Jerzy Gołosz, Mariusz Maziarz, Andrew Moore, Javier Suárez, Piotr Łukasik, Walter Veit, Martin Zach, and two anonymous reviewers for useful comments that have substantially improved the clarity and content of this paper. This work was financed by a National Science Centre OPUS Grant, no. 2017/27/B/HS1/00290. My work is supported as well by the Foundation for Polish Science (FNP). Special thanks to my neighbour, Anna
Bułat, who brought me cheesecake and probiotics during the lockdown. All I did with the former was eat it; the latter, however, served me as an inspiration to begin thinking about the subject of this paper. She as well assisted in preparing a graphical abstract.

\section{DATA AVAILABILITY STATEMENT}

Data sharing not applicable to this article as no datasets were generated or analysed during the current study.

\section{CONFLICT OF INTEREST}

The author declares no conflicts of interest.

\section{ORCID}

Adrian Stencel (D) https://orcid.org/0000-0002-3933-2059

\section{REFERENCES}

1. Pappas, G., Kiriaze, I. J., \& Falagas, M. E. (2008), Insights into infectious disease in the era of Hippocrates. Int. J. Infect. Dis., 12(4), 347350.

2. Cannell, J. J., Vieth, R., Umhau, J., Holick, M., Grant, W. B., Madronich, S., ... Giovannucci, E. (2006), Epidemic influenza and vitamin D. Epidemiol. Infect., 134(6), 1129-1140.

3. Shaman, J., Pitzer, V. E., Viboud, C., Grenfell, B. T., ... Lipsitch M. (2010), Absolute humidity and the seasonal onset of influenza in the continental United States. PLoS Biol., 8(2), e1000316.

4. Martinez, M. E. (2018), The calendar of epidemics: Seasonal cycles of infectious diseases. PLoS Pathog., 14(11), e1007327.

5. Oberg, A. L., Ferguson, J. A., McIntyre, L. M., \& Horner, R. D. (2000), Incidence of stroke and season of the year: Evidence of an association. Am. J. Epidemiol., 152(6), 558-564.

6. London, W. P., \& Yorke, J. A. (1973), Recurrent outbreaks of measles, chickenpox and mumps: I. seasonal variation in contact rates. Am. J. Epidemiol., 98, (6), 453-468.

7. Martinez-Bakker, M., King, A., \& Rohani, P. (2015), Unraveling the transmission ecology of polio. PLoS Biol., 13(6), e1002172.

8. Weinberger, D. M., Grant, L. R., Steiner, C. A., Weatherholtz, R., Santosham, M., Vibound C., \& O'Brien, K. L. (2014), Seasonal drivers of pneumococcal disease incidence: Impact of bacterial carriage and viral activity. Clin. Infect. Dis., 58(2), 188.

9. Dowell, S. F., Whitney, C. G., Wright, C., Rose, C. E., \& Schuchat A. (2003), Seasonal patterns of invasive pneumococcal disease. Emerg. Infect. Dis., 9, 573-579.

10. Levy, K., Hubbard, A. E., \& Eisenberg, J. N. S. (2009), Seasonality of rotavirus disease in the tropics: A systematic review and metaanalysis. Int. J. Epidemiol., 38(6), 1487-1496.

11. Skajaa, N., Erzsébet, H - P., Adelborg, K., Bøtker, H. S., \& Sørensen, H. T. (2019), Lack of seasonality in occurrence of pericarditis, myocarditis, and endocarditis. Ann. Epidemiol., 37, 77-80.

12. Fares, A. (2015), Seasonality of hepatitis: A review update. Fam. Med. Prim. Care Rev., 4(1), 96.

13. Sajadi, M. M., Habibzadeh, P., Vintzileos, A., Shokouhi, S., MirallesWilhelm, F., Amoroso, A. (2020), Temperature and latitude analysis to predict potential spread and seasonality for COVID-19. SSRN Electronic Journal, 20, 20-37.

14. Gaunt, E. R., Hardie, A., Claas, E. C., Simmonds, P., \& Templeton, K. E. (2010), Epidemiology and clinical presentations of the four human coronaviruses 229E, HKU1, NL63, and OC43 detected over 3 years using a novel multiplex real-time PCR method. J. Clin. Microbiol., 48(8), 2940-2947.

15. Söderlund, R., Jernberg, C., Trönnberg, L., Pääjärvi, A., Ågren, E., \& Lahti, E., (2019), Linked seasonal outbreaks of Salmonella 
Typhimurium among passerine birds, domestic cats and humans, Sweden, 2009 to 2016. Euro Surveill., 24(34), 1900074.

16. Stagegaard, J., Kurth, A., Stern, D., Dabrowski, P. W., Pocknell, A., Nitsche, A., Schrick L. (2017), Seasonal recurrence of cowpox virus outbreaks in captive cheetahs (Acinonyx jubatus). PLoS One, 12(11), e0187089.

17. Turner, W. C., Imologhome, P., Havarua, Z., Kaaya, G. P., Mfune, J. K. E., Mpofu I. D. T., \& Getz W. M. (2013), Soil ingestion, nutrition and the seasonality of anthrax in herbivores of Etosha National Park. Ecosphere, 4(1), art13.

18. Runckel, C., Flenniken, M. L., Engel, J. C., Ruby, J. G., Ganem D., Andino, R., \& DeRisi, J. L (2011), Temporal analysis of the honey bee microbiome reveals four novel viruses and seasonal prevalence of known viruses, nosema, and crithidia. PLoS One, 6(6), e20656.

19. Watters, J. L., McMillin, S. L., Marhanka, E. C., Davis, D. R. (2019), Seasonality in Batrachochytrium dendrobatidis detection in amphibians in central Oklahoma, USA. J. Zoo Wildl. Med., 50, 492-497.

20. Adit, G., Mansbach, J., \& Camargo C. (2009), Association between serum 25-hydroxyvitamin $\mathrm{D}$ level and upper respiratory tract infection in the Third National Health and Nutrition Examination Survey. Arch. Intern. Med., 169(4), 384-390.

21. Mounts, A. W., Ando, T., Koopmans, M., Bresee, J. S., Noel, J., \& Glass, R. I. (2000), Cold weather seasonality of gastroenteritis associated with Norwalk-like viruses. J. Infect. Dis., 181, S284-S287.

22. Grassly, N. C., \& Fraser, C. (2006),. Seasonal infectious disease epidemiology. Proc. Royal Soc. B, 273, 2541-2550.

23. Finkenstadt, B. F., \& Grenfell, B. T. (2000), Time series modelling of childhood diseases: A dynamical systems approach. Appl. Stat., 49, 182-205.

24. Fares, A. (2013), Factors influencing the seasonal patterns of infectious diseases. Int. J. Prev. Med., 4(2), 128-132.

25. Fisman, D. N. (2007), Seasonality of infectious diseases. Annu. Rev. Public Health, 28, 127-143.

26. Moriyama, M., Hugentobler, W. J., \& Iwasaki, A. (2020), Seasonality of respiratory viral infections. Annu. Rev. Virol., 7, 83.

27. Maurice, C., Knowles, C. L., Ladau, S. J., Pollard, K. S., Fenton A., Pedersen, A. B., \& Turnbaugh, P. J. (2015), Marked seasonal variation in the wild mouse gut microbiota. ISME J., 9, 2423-2434.

28. Novakowa, E., Woodhams, D., Rodríguez-Ruano, S. M., Brucker, R., Leff, J. W., Maharaj J., ... Scott, J. (2017), Mosquito microbiome dynamics, a background for prevalence and seasonality of West Nile Virus. Front. Microbiol., 8, 526.

29. Longo, A. V., Savage A. E., lan, H., \& Zamudio, K. R., (2015),. Seasonal and ontogenetic variation of skin microbial communities and relationships to natural disease dynamics in declining amphibians. R. Soc. Open Sci., 2, 140377.

30. Gohli, J., Bøifot, K. O., Moen, L. V., Pastuszek, P., Skogan, G., Udekwu, K. I., \& Dybwad M. (2019), The subway microbiome: Seasonal dynamics and direct comparison of air and surface bacterial communities. Microbiome, 7, 160.

31. Sender, R., Fuchs, S., \& Milo, R. (2016), Revised estimates for the number of human and bacteria cells in the body. PLoS Biol., 14(8), e1002533.

32. Sekirov, I., Russell, S. L., Antunes, L. C., \& Finlay, B. B. (2010), Gut microbiota in health and disease. Physiol. Rev., 90(3), 859-904.

33. Lazar, V., Ditu, L. M., Pircalabioru, G. G., Gheorghe, I., Curutiu, C., Holban, A. M. ... Chifiriuc, M. C (2018), Aspects of gut microbiota and immune system interactions in infectious diseases, immunopathology, and cancer. Front. Immunol., 9, 1830.

34. Zilber-Rosenberg, I., \& Rosenberg, E. (2008), Role of microorganisms in the evolution of animals and plants: The hologenome theory of evolution. FEMS Microbiol. Rev., 32(5), 723-735.

35. Stencel, A., \& Wloch-Salamon, D. M. (2018), Some theoretical insights into the hologenome theory of evolution and the role of microbes in speciation. Theory Biosci., 137(2), 197-206.
36. Suárez, J. (2020), The stability of traits conception of the hologenome: An evolutionary account of holobiont individuality. HPLS, 42(11).

37. Ley, R., Lozupone, C., Hamady, M., Knight, R., \& Gordon J. I. (2008), Worlds within worlds: Evolution of the vertebrate gut microbiota. Nat. Rev. Microbiol., 6, 776-788.

38. Pradeu, T. (2011), A mixed self: The role of symbiosis in development. Biol. Theory, 6(1), 80-88.

39. Suárez, J., \& Stencel, A. (2020), A part-dependent account of biological individuality: Why holobionts are individuals and ecosystems simultaneously. Biol. Rev., 95(5), 1308-1324.

40. Clarke, G., Stilling, R., Paul, J., Kennedy, P., Stanton, C., Cryan, J. F., \& Dinan, T. G. (2014), Minireview: Gut microbiota: The neglected endocrine organ. Mol. Endocrinol., 28(8), 1221-1238.

41. Larsbrink, J., Rogers, T., Hemsworth, G., McKee, L., Tauzin, A. S., Spadiut, O., ... Brumer, H. (2014), A discrete genetic locus confers xyloglucan metabolism in select human gut Bacteroidetes. Nature, 506, 498-502.

42. Shreiner, A. B., Kao, J. Y., \& Young, V. B. (2015), The gut microbiome in health and in disease. Curr. Opin. Gastroenterol., 31(1), 69-75.

43. Harris, R., Brucker, R., Walke, J., Becker, M. H., Schwantes, C. R., ... Minbiole, K. P. C (2009), Skin microbes on frogs prevent morbidity and mortality caused by a lethal skin fungus. ISME J., 3, 818-824.

44. Woodhams, D. C., Bosch, J., Briggs, C. J., Cashins, S., Davis, L. R., \& Lauer, A., ... Voyles, J. (2011), Mitigating amphibian disease: Strategies to maintain wild populations and control chytridiomycosis. Front. Zool., 8, 8.

45. Atarashi, K., Tanoue, T., Oshima, K., Suda, W., Nagano, Y., Nishikawa, H. (2013), Treg induction by a rationally selected mixture of Clostridia strains from the human microbiota. Nature, 500(7461), 232-236.

46. Valles-Colomer, M., Falony, G., Darzi, Y., Tigchelaar, F. T., Wang, J., Tito, R. Y., ... Raes, J. (2019), The neuroactive potential of the human gut microbiota in quality of life and depression. Nat. Microbiol., 4, 623-632.

47. Chiu, L., Bazin, T., Truchetet, M. E., Schaeverbeke, T., Delhaes, L., \& Pradeu, T. (2017), Protective microbiota: From localized to longreaching co-immunity. Front. Immunol., 8, 1678.

48. Pradeu, T. (2020), Philosophy of biology: Immunology and individuality. eLife, 8, e47384.

49. Zhang, B., Chassaing, B., Shi, Z., Uchiyama, R., Denning, T. L., Crawford, S. E., ... Gewirtz (2014), Viral infection. Prevention and cure of rotavirus infection via TLR5/NLRC4-mediated production of IL-22 and IL-18. Science, 346(6211), 861-865.

50. Rolhion, N., \& Chassaing, B. (2016), When pathogenic bacteria meet the intestinal microbiota. Philos. Trans. R. Soc. Lond. B: Biol. Sci., 371(1707), 20150504.

51. Russell, S. L., Gold, M. J., Hartmann, M., Willing, B. P., Thorson, L., Wlodarska, M., ... Finlay, B. B. (2012), Early life antibiotic-driven changes in microbiota enhance susceptibility to allergic asthma. Embo Rep., 13, 440-447.

52. Parashar, U. D., Gibson, C. J., Bresee, J. S., \& Glass, R. I. (2006), Rotavirus and severe childhood diarrhea. Emerg. Infect. Dis., 12, 304306.

53. Zeng, H., Carlson, A. Q., Guo, Y., \& Yu, Y. (2003), Flagellin is the major proinflammatory determinant of enteropathogenic Salmonella. J. Immunol., 171, 3668-3674.

54. Greenberg H. B., \& Estes, M. K., (2009),. Rotaviruses: From pathogenesis to vaccination. Gastroenterology, 136, 1939-1951

55. Buffie, C. G., \& Pamer, E. G. (2013), Microbiota-mediated colonization resistance against intestinal pathogens. Nat. Rev. Immunol., 13, 790801.

56. Kamada, N., Kim, Y. G., Sham, H. P., Vallance, B. A., Puente, J. L., Martens, E. C., \& Núñez, G. (2012), Regulated virulence controls the ability of a pathogen to compete with the gut microbiota. Science, 336 , 1325-1329. 
57. Kommineni, S., Bretl, D. J., Lam, V., Chakraborty, R., Hayward, M., Simpson, P., ... Salzman, N. H. (2015), Bacteriocin production augments niche competition by enterococci in the mammalian gastrointestinal tract. Nature, 526, 719-722.

58. Rea, M. C., Sit, C. S., Clayton, E., O'Connor, P. M. (2010), Thuricin CD, a posttranslationally modified bacteriocin with a narrow spectrum of activity against Clostridium difficile. Proc. Natl. Acad. Sci. USA, 107, 9352-9357.

59. David, L. A., Maurice, C. F., Carmody, R. N., Gootenberg, D. B., Button, J. E., Wolfe, B. E., ... Turnbaugh, P. J. (2014), Diet rapidly and reproducibly alters the human gut microbiome. Nature, 505(7484), 559563.

60. Hasan, N., \& Yang, H. (2019), Factors affecting the composition of the gut microbiota, and its modulation. PeerJ, 7, e7502.

61. Burke, C., Steinberg, P., Rusch, D., Kjellberg, S. (2011), Bacterial community assembly based on functional genes rather than species. Proc. Natl. Acad. Sci. USA, 108(34), 14288-14293.

62. Sun, B., Wang, X., Bernstein, S., Huffman, M., Xia, D - P., Gu, Z., ... Li, J - H. (2016), Marked variation between winter and spring gut microbiota in free-ranging Tibetan Macaques (Macaca thibetana). Sci. Rep., 6, 26035.

63. Isaac, S., Scher, J. U., Djukovic, A., Jiménez, N., Littman, D. R., Abramson, S. B. ... Ubeda, C. (2017), Short-and long-term effects of oral vancomycin on the human intestinal microbiota. J. Antimicrob. Chemother., 72(1), 128-136.

64. Walker, A. W., Ince, J., Duncan, S. H., Webster, L. M., Holtrop, G., Ze, X., ... Flint, H. J. (2011), Dominant and diet-responsive groups of bacteria within the human colonic microbiota. ISME J., 5(2), 220-230.

65. Rampelli, S., Schnorr, S., Consolandi, C., Turroni, S., Severgnini, M., Peano, C., ... Candela, M. (2015), Metagenome sequencing of the Hadza hunter-gatherer gut microbiota. Curr. Biol., 25, 1682-1693.

66. Fontaine, S. S., Novarro, A. J., \& Kohl, K. D. (2018), Environmental temperature alters the digestive performance and gut microbiota of a terrestrial amphibian. J. Exp. Biol., 221, 187-559.

67. Sepulveda, J., \& Moeller, A. H. (2020), The effects of temperature on animal gut microbiomes. Front. Microbiol., 11, 384.

68. Chevalier, C., Stojanovic, O., Colin, D. J., Suarez-Zamorano, N., Tarallo, V., Veyrat-Durebex, C., ... Trakjovski, M. (2015), Gut microbiota orchestrates energy homeostasis during cold. Cell, 163, 13601374.

69. Tajima, K., Nonaka, I., Higuchi, K., Takusari, N., Kurihara, M., Takenaka, A., ... Aminov, R. Influence of high temperature and humidity on rumen bacterial diversity in Holstein heifers. Anaerobe, 2007, 13(2), 57-64.

70. Zhong, S., Ding, Y., Wang, Y., Zhou, G., Guo, H., Chen, Y., \& Yang, Y. (2019), Temperature and humidity index (THI)-induced rumen bacterial community changes in goats. Appl. Microbiol. Biotechnol., 103, 103, 3193-3203.

71. Waterhouse, M., Hope, B., Krause, L., Morrison, M., Protani, M. M., Zakrzewski, M., Neale, R. E. (2019), Vitamin D and the gut microbiome: A systematic review of in vivo studies. Eur. J. Nutr., 58(7), 2895-2910.

72. Hewison, M. (2011), Antibacterial effects of vitamin D. Nat. Rev. Endrocrinol., 7, 336-344

73. Koliada, A., Moseiko, V., Romanenko, M., Piven, L., Lushchak, O., Kryzhanovska, N., ... Vaiserman, A. (2020), Seasonal variation in gut microbiota composition: Cross-sectional evidence from Ukrainian population. BMC Microbiol. [Electronic Resource], 20, 100

74. Davenport, E. R., Mizrahi-Man, O., Michelini, K., Barreiro, L. B., Ober, C., \& Gilad, Y. (2014), Seasonal variation in human gut microbiome composition. PLoS One, 9(3), e90731.

75. Suda, K. J., Hicks, L. A., Roberts, R. M., Hunkler, R. J., \& Taylor, T. H. (2014), Trends and seasonal variation in outpatient antibiotic prescription rates in the United States, 2006 to 2010. Antimicrob. Agents. Chemother., 58(5), 2763-2766.
76. Caucci, S., Karkman, A., Cacace, D., Rybicki, M., Timpel, P., Voolaid, V., ... Berendonk, T. U. (2016), Seasonality of antibiotic prescriptions for outpatients and resistance genes in sewers and wastewater treatment plant outflow. FEMS Microbiol. Ecol., 92(5), fiw060.

77. Smits, S. A., Leach, J., Sonnenburg, E. D., Gonzales, C. G., Lichtman, J. S., Reid, G., ... Sonnenburg, J. L. (2017), Seasonal cycling in the gut microbiome of the Hadza hunter-gatherers of Tanzania. Science, 357(6353), 802-806.

78. Hisada, T., Endoh, K., \& Kuriki, K. (2015), Inter- and intra-individual variations in seasonal and daily stabilities of the human gut microbiota in Japanese. Arch. Microbiol., 197(7), 919-934.

79. Zhang, J., Guo, Z., Lim, A. A., Zheng, Y., Koh, E., Ho, D., ... Zhang, H. (2015), Mongolians core gut microbiota and its correlation with seasonal dietary changes. Sci. Rep., 4, 5001.

80. Korownyk, C., Liu, F., \& Garrison, S. (2018), Population level evidence for seasonality of the human microbiome. Chronobiol. Int., 35(4), 573577.

81. Ou, T., Xu, W., Wang, F., Strobel, G., Zhou Z - Y., Xiang, Z - H., ... Xie, J. (2019), A microbiome study reveals seasonal variation in endophytic bacteria among different mulberry cultivars. Comput. Struct. Biotechnol., 17, 1091-1100.

82. Copeland, J. K, Yuan, L., Layeghifard, M., Wang, P. W., \& Gutman, D. (2015), Seasonal community succession of the phyllosphere microbiome. Mol. Plant Microbe Interact., 28(3), 274-285.

83. Fischbach, M. A. (2018), Microbiome: Focus on causation and mechanism. Cell, 174(4), 785-790.

84. Bourrat, P. (2018), Have causal claims about the gut microbiome been over-hyped? BioEssays, 40(12), 1800178

85. Lynch, K. E., Parke, E. C., \& O’Malley, M. A. (2019), How causal are microbiomes? A comparison with the helicobacter pylori explanation of ulcers. Biol. Philos., 34, 62.

86. Groves, H. T., Higham, S. L., Moffatt, M. F., Michael, J., Cox, Tregoning, J. S. (2020), Respiratory viral infection alters the gut microbiota by inducing inappetence. mBio, 11(1), e03236-19.

87. Vila, V. A., Collij, V., Sanna, S., Sinha, T., Imhann, F., Bourgonje, A. R. (2020), Impact of commonly used drugs on the composition and metabolic function of the gut microbiota. Nat. Commun., 11, 362.

88. Wroński, L., \& Marczyk, M. (2010), Only countable reichenbachian common cause systems exist. Found. Phys., 40(8), 1155-1160.

89. Maziarz, M. (2020), The philosophy of causality in economics. Causal Inferences and Policy Proposals. Routledge, London.

90. Sanders, G. J., Łukasik, P., Frederickson, M. E., Russell, J. A., Koga, R., Knigh, B., \& Pierce, N. E. (2017), Dramatic differences in gut bacterial densities correlate with diet and habitat in rainforest ants. Integr. Comp. Biol., 57(4), 705-722.

91. Trompette, A., Gollwitzer, E. S., Yadava, K., Anke, K., Sichelstiel, A. K., Sprenger, N., ... Marsland, B. J. (2014), Gut microbiota metabolism of dietary fiber influences allergic airway disease and hematopoiesis. Nat. Med., 20, 159-166.

92. Desai, M. S., Seekatz, A. M., Koropatkin, N. M., Kamada, N., Hickey, C. A., Wolter, M., ... Martens, E. C. (2016), A dietary fiber-deprived gut microbiota degrades the colonic mucus barrier and enhances pathogen susceptibility. Cell, 167, 1339-1353.e21.e21.

93. Pena, J. A., Rogers, A. B., Ge, Z., Ng, V., Sandra, Y., Fox, J. G. and Versalovic, J. (2005),. Probiotic Lactobacillus spp. diminish Helicobacter hepaticus-induced inflammatory bowel disease in interleukin-10deficient mice. Infect. Immun., 73, 912-920.

94. Eaton, K. A., Honkala, A., Auchtung, T. A., \& Britton, R. A. (2011), Probiotic Lactobacillus reuteri ameliorates disease due to enterohemorrhagic Escherichia coli in germfree mice. Infect. Immun., 79, 185-191.

95. Cannell, J. J., Vieth, R., Umhau, J., Holick, M., Grant, W. B., Mandronich S., ... Giovannucci E. (2006), Epidemic influenza and vitamin D. Epidemiol. Infect., 134(6), 1129-1140.

96. Prietl, B., Treiber, G., Pieber, T. R., \& Amrein, K. (2013), Vitamin D and immune function. Nutrients, 5(7), 2502-2521. 
97. Autier, P., Boniol, M., Pizot, C., \& Mullie, P. (2014), Vitamin D status and ill health: A systematic review. Lancet Diabetes Endocrinol., 2, 7689.

98. Lowen, A. C., \& Steel, J. (2014), Roles of humidity and temperature in shaping influenza seasonality. J. Virol., 88(14), 7692.

99. Eccles, R. (2002), An explanation for the seasonality of acute upper respiratory tract viral infections. Acta Oto-Laryngol., 122, 183-191.

100. Moriyama, M., \& Ichinohe, T. (2019), High ambient temperature dampens adaptive immune responses to influenza $A$ virus infection. Proc. Natl. Acad. Sci. U. S. A., 116(8), 3118-3125.

101. Fox, S. J., Miller, J. C., \& Meyers, L. A., (2017), Seasonality in risk of pandemic influenza emergence. Plos Comput. Biol., 13, e1005749.

102. Ferguson, L. V., Dhakal, P., Lebenzon, J., \& Heinrichs, (2018), Seasonal shifts in the insect gut microbiome are concurrent with changes in cold tolerance and immunity. Funct. Ecol., 32, 2357-2368.

103. Ye, Y. H., Carrasco, A. M., Dong, Y., Sgrò, C., \& McGraw, E. A. (2016), The effect of temperature on Wolbachia-mediated Dengue virus blocking in Aedes aegypti. Am. J. Trop. Med. Hyg., 94, 812-819.

104. Ciota, A. T., Ehrbar, D. J., Matacchiero, A. C., Van Slyke, G. A., Kramer, L. D. (2013), The evolution of virulence of West Nile virus in a mosquito vector: Implications for arbovirus adaptation and evolution. BMC Evol. Biol. [Electronic Resource], 13, 71.

105. Kambris, Z., Cook, P. E., Phuc, H. K., \& Sinkins S. P. (2009), Immune activation by life-shortening Wolbachia and reduced filarial competence in mosquitoes. Science, 326, 134-136.

106. Hegde, S., Rasgon, J. L., \& Hughes, G. L. (2015), The microbiome modulates arbovirus transmission in mosquitoes. Curr. Opin. Virol., 15, 97102.
107. Gilbert, S., Sapp, J., \& Tauber, A. (2012), A symbiotic view of life: We have never been individuals. Q. Rev. Biol., 87(4), 325341.

108. Ronai, I., Greslehner, G. P., Boem, F., Carlisle, J., Stencel, A., Suárez, S., ... Zacks, O. (2020), Microbiota, symbiosis and individuality summer school" meeting report. Microbiome, 8, 117.

109. Smith, A. H., Łukasik, P., O'Connor, M. P., Lee, A., Mayo, G., Drott, M. T., ... Russell, J. A. (2015), Patterns, causes and consequences of defensive microbiome dynamics across multiple scales. Mol. Ecol., 24, 1135-1149.

110. Roughgarden, J., Gilbert, S. F., Rosenberg, E., Zilber-Rosenberg, I., Lloyd, E. A (2018), Holobionts as units of selection and a model of their population dynamics and evolution. Biol. Theory, 13, 44-65.

111. Lloyd, E., \& Wade, M. J. (2019), Criteria for holobionts from community genetics. Biol. Theory, 14, 151-170.

112. Gil, S., Segal, D., Ringo, J. M., Abraham, H. A., Zilberg-Rosenberg I., Zilberg-Rosenberg, E. (2010), Commensal bacteria play a role in mating preference of Drosophila melanogaster. Proc. Natl. Acad. Sci. U. S. A., 107(46), 20051-20056.

How to cite this article: Stencel, A. (2020). Do seasonal microbiome changes affect infection susceptibility, contributing to seasonal disease outbreaks? BioEssays, e2000148. https://doi.org/10.1002/bies.202000148 